\section{Fremtidens hjerneslagdiagnostikk og hjerneslagimitatorer}

KRONIKK

\section{KASHIF WAQAR FAIZ}

E-post: kashif.faiz@ahus.no Kashif Waqar Faiz er spesialist i nevrologi, ph.d., master i helseadministrasjon og seksjonsleder/overlege og forsker ved henholdsvis Nevroklinikken og Avdeling for helsetjenesteforskning, Akershus universitetssykehus.

Forfatteren har fylt ut ICMJE-skjemaet og oppgir ingen interessekonflikter.

\section{KIM RAND}

Kim Rand er psykolog, ph.d. og seniorforsker ved Avdeling for helsetjenesteforskning, Akershus universitetssykehus. Han arbeider med matematisk modellering, helseøkonomi og livskvalitetsforskning.

Forfatteren har fylt ut ICMJE-skjemaet og oppgir følgende interessekonflikter: Han har mottatt stipend fra Forskningsrådet for prosjektet Modelling treatment and rehabilitation of stroke patients simulation to evaluate the present and plan for the future.

\section{MATHIAS BARRA}

Mathias Barra er ph.d. i matematisk logikk og seniorforsker ved Avdeling for helsetjenesteforskning, Akershus universitetssykehus. Han arbeider med matematisk modellering av pasientforløp, helseøkonomi, statistikk og livskvalitetsforskning. Forfatteren har fylt ut ICMJE-skjemaet og oppgir følgende interessekonflikter: Han har mottatt stipend fra Forskningsrådet for prosjektet Modelling treatment and rehabilitation of stroke patients simulation to evaluate the present and plan for the future.

Riktig og tidlig behandling av hjerneslag er godt investerte ressurser. Men hvordan kan vi bedre skille hjerneslag fra hjerneslagimitatorer? Mange pasienter med hjerneslagimitatorer får bedre pasientforløp dersom tidlig diagnostikk forbedres. 


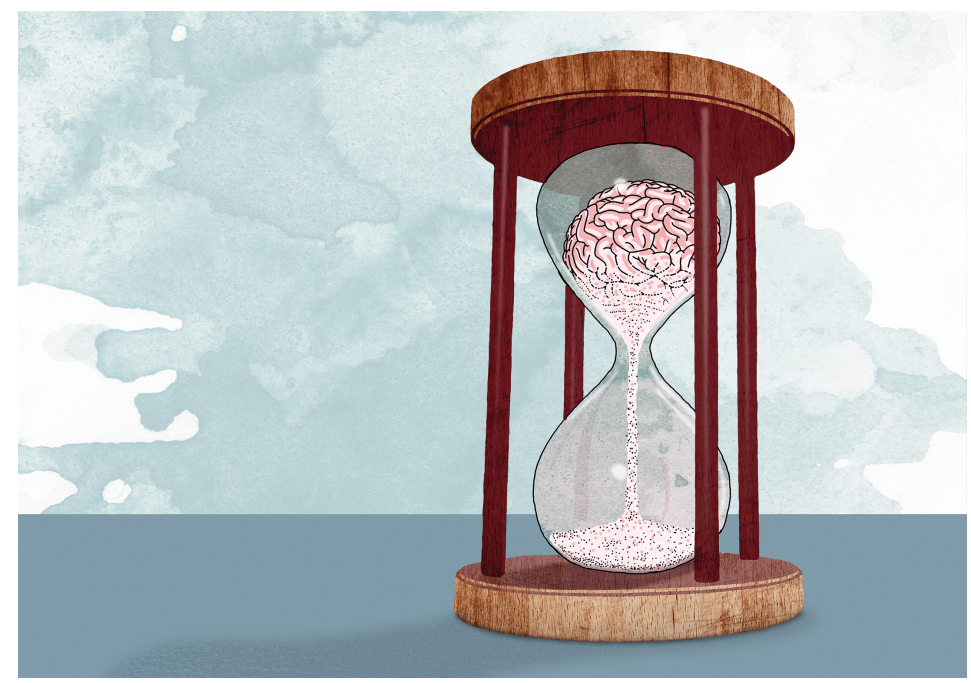

Illustrasjon: Ørjan Jenssen/Superpop

Hjerneslag gir svært ulike symptomer og er en klinisk diagnose med akutt innsettende symptomer som tilsvarer nevrologisk funksjonstap. I akuttfasen kreves en CT-undersøkelse for å skille mellom hjerneinfarkt og hjerneblødning. CT caput har høy sensitivitet og spesifisitet for å oppdage en fersk hjerneblødning, mens de iskemiske forandringene ved et hjerneinfarkt ofte ikke er synlige før flere timer etter symptomdebut.

Det har vært økt søkelys på hjerneslag de senere årene, med etableringen av Nasjonalt hjerneslagregister (1), innføring av flere nasjonale kvalitetsindikatorer for hjerneslagbehandling (2), ny nasjonal faglig retningslinje for behandling og rehabilitering ved hjerneslag (3), nasjonal opplysningskampanje om hjerneslag (4) og senest pakkeforløp for hjerneslag (5).

\section{Tid er hjerne}

God akuttbehandling av hjerneslag krever et effektivt prehospitalt forløp, hurtig diagnostikk i akuttmottak og innleggelse i slagenhet for videre diagnostikk og behandling.

For hjerneinfarkt er intravenøs trombolyse og trombektomi effektive behandlingsalternativer, men som må effektueres innenfor snevre tidsvinduer. Effekten er bedre jo tidligere behandlingen settes i gang, og prognosetapet er dermed betydelig ved forsinket behandlingsstart $(6,7)$.

«Tid er hjerne» er blitt et etablert uttrykk som fremhever at hjerneslag har gått fra å være «skuldertrekksmedisin» til «blålysmedisin» på få tiår.

For å unngå at pasienter med hjerneslag kommer for sent til tidskritisk behandling - med betydelig prognosetap som konsekvens - er det ønskelig med svært lav terskel for innleggelse i sykehus ved symptomer på hjerneslag. Et slikt ønske reflekteres tydelig i den nylig publiserte nasjonale retningslinjen (3): «[d]et skal øyeblikkelig settes i gang tiltak som sikrer at pasienter med symptomer på akutt hjerneslag raskt blir transportert til sykehus», at også "pasienter med symptomer på TIA [transitorisk iskemisk anfall] innlegges akutt for utredning og behandling», og at "[s]pesialisthelsetjenesten har plikt til å straks ta imot en pasient med symptomer på hjerneslag». Tidsaspektet gjenspeiles også ved at «andel pasienter som får trombolyse» og «trombolyse av hjerneinfarkt innen 40 minutter» nå er inkludert som nasjonale kvalitetsindikatorer (2).

Samtidig vet vi at behandling i slagenhet er den viktigste komponenten for å redusere dødelighet og funksjonshemning på kort og lengre sikt. En slagenhet defineres som en geografisk avgrenset enhet med faste senger, bemannet med tverrfaglig, spesialopplært personale og med et standardisert program for diagnostikk, observasjon, akuttbehandling, tidlig mobilisering og rehabilitering av pasienter med hjerneslag (3). 


\section{Hjerneslagimitatorer}

En betydelig andel av pasientene som legges inn med symptomer på hjerneslag, viser seg å ha andre tilstander. Symptombilder som ligner på hjerneslag, men som viser seg å ha en annen årsak, kalles hjerneslagimitatorer (stroke mimics). Studier viser at mellom 20 og 40 \% av pasientene som legges inn med hjerneslag som tentativ diagnose, viser seg å ha hjerneslagimitatorer (8). I en studie med over 8 ooo pasienter over en tiårsperiode, ble $30 \%$ av pasientene diagnostisert med hjerneslagimitatorer (9). Både demografiske faktorer (yngre, flere kvinner) og mangel på risikofaktorer for hjerneslag (hypertensjon, hyperlipidemi, atrieflimmer og koronarsykdom) er forbundet med hjerneslagimitator som endelig diagnose, hvor mangel på risikofaktorer var den sterkeste forklaringsvariabelen i denne studien (9).

I en nylig publisert artikkel, med data fra slagenheten ved Akershus universitetssykehus, ble det vist at $38 \%$ av pasientoppholdene resulterte i andre diagnoser enn hjerneslag eller transitorisk iskemisk anfall (10). Hjerneslagimitatorgruppen var heterogen, og omtrent $27 \%$ av pasientene hadde symptom- eller observasjonsdiagnoser. Disse diagnosene settes ofte i mangel på andre mer presise diagnoser, når man ikke med rimelig sikkerhet kan sette en diagnose for en annen tilstand. Det var flere MR-undersøkelser blant pasienter med hjerneslagimitatorer enn det var hos pasienter med hjerneslag.

\section{Insidens, sensitivitet og spesifisitet}

Kombinasjonen av $\emptyset \mathrm{kt}$ søkelys på raskere innleggelse av pasienter, og en befolkning med bedre kunnskaper om symptomer på hjerneslag, vil på den ene siden medføre at flere pasienter kan få effektiv behandling i tide: Sensitiviteten til helsetjenesten, med tanke på å oppdage hjerneslag, vil bedres. På den annen side kan vi med høy grad av sikkerhet si at dette også vil medføre at flere pasienter med hjerneslagimitatorer blir innlagt:Spesifisiteten vil svekkes.

Grunnet befolkningsøkning og spesielt økning i antall og andel eldre de neste tiårene, forventes en betraktelig økning i antall hjerneslagtilfeller i fremtiden (11). En slik økning forutsetter at aldersjustert insidens holdes fast. De siste tiårene er det likevel blitt observert en fallende hjerneslaginsidens (12), noe som kan skyldes bedre folkehelse og tiltak rettet mot bedre forebygging av hjerneslag. Dette kan i noen grad kompensere for «eldrebølgen» (13), men det er vanskelig å forutsi hvor lenge trenden fortsetter (14). Det forutsetter også fortsatt innsats rettet mot forebygging av hjerneslag og andre hjerte- og karsykdommer, som resulterer i fortsatt fallende hjerneslaginsidens.

Selv med fallende aldersjustert insidens kan vi forvente et høyere innleggelsesvolum, ettersom terskelen for innleggelse senkes, og andelen av befolkningen som anses å være i faresonen, øker. En høyere terskel for innleggelse vil ikke være etisk riktig. Sammen med raskere innleggelse av faktiske hjerneslag kan vi derfor forvente en større andel hjerneslagimitatorer, noe som vil kreve økt ressursinnsats i akuttkjeden for mottak av pasienter med mistanke om hjerneslag; ambulansetransport til sykehus, lege- og sykepleierressurser for håndtering av pasienten i akuttmottaket, men også røntgenfasiliteter og radiologisk kompetanse, i tillegg til senger og bemanning i spesialiserte slagenheter.

Andelen med hjerneslagimitatorer må nødvendigvis inkluderes når fremtidige ressursbehov estimeres, og ressursene må i større grad dreies mot pasientseleksjon - å finne de «riktige» pasientene tidligere i pasientforløpet, slik at pasienter med hjerneslag kan nyttiggjøre seg behandling i slagenhet, og at pasienter med hjerneslagimitatorer raskere får behandling for sine tilstander.

\section{Slagenhet}

Til tross for at behandling i slagenhet er svært ressurskrevende, er det vist at det ikke fører 
til merkostnader - for pasienter med hjerneslag. Selv uten å ta hensyn til helsegevinsten, synes det som om slagenhetsbehandling er besparende, slik at den økte kostnaden betaler seg selv ved kortere opphold og mindre utgifter til behandling på sikt, sammenlignet med innleggelse i en generell medisinsk avdeling $(15,16)$.

På den annen side er diagnostisering og utredning ressurskrevende, og man må ta høyde for at en økende andel av pasientene som innlegges med spørsmål om hjerneslag, viser seg å ha andre sykdommer. Som påpekt over, må man påregne en betydelig andel pasienter med hjerneslagimitatorer, gitt dagens spesifisitet for hjerneslag. De fleste diagnosegruppene, med unntak av svulster i nervesystemet, gir lavere vekt for diagnoserelaterte grupper (DRG) for hjerneslagimitatorer enn hjerneslag. For eksempel vil svimmelhet, den vanligste hjerneslagimitatoren i flere studier, kun gi en tredel av DRG-vekt, sammenlignet med hjerneslag med en bidiagnose. Pasienter med hjerneslagimitatorer vil dermed både oppta senger og bruke ressurser i en slagenhet, og samtidig føre til at slagenheten ikke kompenseres økonomisk i tilstrekkelig grad.

\section{Fremskrivningsscenario}

I beregningen av fremtidige ressursbehov til hjerneslagorganisering og -behandling er det viktig å være klar over at en betydelig andel av pasientene vil vise seg ikke å ha hjerneslag. Man kan avklare hva noen av pasientene lider av allerede prehospitalt eller i akuttmottaket, men de fleste krever innleggelse og utredning i slagenhet før hjerneslag kan utelukkes.

MR-unders $ø$ kelse har samme grad av sensitivitet for hjerneblødning som CT-unders $ø$ kelse, men kan avdekke hjerneinfarkt langt tidligere. MR-bilder tatt i akuttfasen kunne sannsynligvis raskt ha avklart om pasienten har et hjerneinfarkt eller ikke, slik at en større andel av pasientene kunne mottatt adekvat behandling uten innleggelse i en slagenhet. $\emptyset \mathrm{kt}$ bruk av MR-undersøkelse i akuttfasen, også for pasienter som ikke er kandidater for intravenøs trombolyse, krever en helt annet logistikk og radiologisk beredskap. Per i dag er det derfor ikke kapasitet til å kunne tilby MR-undersøkelse som en «screeningundersøkelse» ved usikkerhet rundt diagnosen ved de fleste sykehus, men det bør undersøkes om økt MR-kapasitet kan bidra til at man kan finne ut hva som feiler flere pasienter i akuttfasen, slik at de ikke har behov for videre innleggelse og utredning $\mathrm{i}$ en slagenhet. Da kan man bruke slagenhetens ressurser på pasienter med hjerneslag og transitorisk iskemisk anfall.

Som tidligere beskrevet, har hjerneslaginsidensen falt de siste tiårene. Samtidig forventes en $ø$ kning i hjerneslagimitatorer. I et fremskrivningsscenario med 1 \% årlig reduksjon i nye hjerneslagtilfeller, og 1 \% årlig økning i antall nye tilfeller med hjerneslagimitatorer, blir antall innleggelser med hjerneslagimitatorer høyere enn antall innleggelser med hjerneslag allerede i 2020 for kvinner og i 2035 for menn (10). Det er derfor grunn til å fokusere på hvordan man trygt kan øke akuttkjedens spesifisitet for hjerneslag.

\section{Fremtidig forskning}

Hjerneslag og transitorisk iskemisk anfall rammer vidt, og det er stor forskjell på pasientene. Man kan øke spesifisiteten ved bedre å identifisere de pasientene som ikke har nytte av innleggelse i en slagenhet. En slik mulighet kan dog ikke prøves ut uten at kunnskapsgrunnlaget utvides. Frem til nyere skåringsinstrumenter for prognose uten innleggelse er klinisk validert i den norske akuttkjeden, må dagens praksis opprettholdes.

Imidlertid kan utviklingen tyde på at mer forskning på hvilke pasienter som trygt kan henvises til mindre ressurskrevende oppfølging ved mistanke om hjerneslag, vise seg å være svært viktig i en stadig mer presset sykehusøkonomi og -kapasitet. I slik forskning må man konsentrere seg om både kliniske og epidemiologiske parametere, men også om eksisterende og nye biomarkører, i tillegg til kostnadseffektivitet ved økt og tidligere radiologisk innsats.

Hjerneslagimitatorer fortrenger ressurser som har svært høy alternativkostnad. Studier 
med mål om å bedre tidlig identifisering av hjerneslagimitatorer bør ha stor interesse av flere grunner: Det vil hindre feilinnleggelser av pasienter med hjerneslagimitatorer som ikke krever innleggelse, $\varnothing$ ke sannsynligheten for at pasienter med hjerneslagimitatorer som krever innleggelse, kommer tidligere til rett behandling, samt frigjøre kapasitet for dem som trenger det mest, nemlig pasientene med hjerneslag.

\section{LITTERATUR:}

1. Norsk Hjerneslagregister. Årsrapport 2016. Trondheim: Nasjonalt sekretariat for Norsk hjerneslagregister; 2017.

https://stolav.no/Medisinskekvalitetsregistre/Norsk-hjerneslagregister/\%C3\%85rsrapport2016-Norsk-hj erneslagregister.pdf(12.1.2018).

2. Helsedirektoratet. Eksisterende nasjonale kvalitetsindikatorer.

https://helsedirektoratet.no/statistikk-og-analyse/kvalitetsindikatorer/eksisterende-nasjonale-kvalitet sindikatorer (12.1.2018)

3. Indredavik B. Nasjonal fagligretningslinje for behandling og rehabilitering ved hjerneslag. Oslo: Helsedirektoratet, 2017. https://helsedirektoratet.no/Retningslinjer/Hjerneslag.pdf(3.1.2018).

4. Helsedirektoratet. Plutselig vanskelig å prate, smile eller løfte armene? Ring 113! https://helsedirektoratet.no/nyheter/plutselig-vanskelig-a-prate-smile-eller-lofte-armene-ring-113 (25.1.2018).

5. Indredavik B, Næss H, Salvesen R et al. Pakkeforløp for behandling og rehabilitering ved hjerneslag. Oslo: Helsedirektoratet, 2017.

https://helsedirektoratet.no/Retningslinjer/Hjerneslag\%20\%E2\%80\%93\%2opakkeforl\%C3\%B8p\%2O(Fase\% 201).pdf(12.1.2018).

6. ATLANTIS Trials Investigators. Association of outcome with early stroke treatment: pooled analysis of ATLANTIS, ECASS, and NINDS rt-PA stroke trials. Lancet 2004;363: 768 - 74. [PubMed][CrossRef]

7. Saver JL. Time is brain-quantified. Stroke 2006; 37: 263 - 6. [PubMed][CrossRef]

8. Gibson LM, Whiteley W. The differential diagnosis of suspected stroke: a systematic review. J R Coll Physicians Edinb 2013; 43: 114 - 8. [PubMed][CrossRef]

9. Merino JG, Luby M, Benson RT et al. Predictors of acute stroke mimics in 8187 patients referred to a stroke service. J Stroke Cerebrovasc Dis 2013; 22: e397-403. [PubMed][CrossRef]

10. Faiz KW, Labberton AS, Thommessen B et al. The burden of stroke mimics: present and future projections. J Stroke Cerebrovasc Dis 2018; 27: 1288 - 95.

11. Statens Helsetilsyn. Scenario 2030 - Sykdomsutviklingen for eldre fram til 2030. Rapport 6-99 i Helsetilsynets utredningsserie, 1999.

https://www.helsetilsynet.no/upload/Publikasjoner/utredningsserien/203o_sykdomsutvikling_eldre_ ik-2696.pdf(19.1.2018).

12. Feigin VL, Forouzanfar MH, Krishnamurthi R et al. Global and regional burden of stroke during 1990-2010: findings from the Global Burden of Disease Study 2010. Lancet 2014;383: 245 - 54.

[PubMed][CrossRef]

13. Modig K, Drefahl S, Andersson T et al. The aging population in Sweden: can declining incidence rates in MI, stroke and cancer counterbalance the future demographic challenges? Eur J Epidemiol 2012; 27: 139 - 45. [PubMed][CrossRef]

14. Elkins JS, Johnston SC. Thirty-year projections for deaths from ischemic stroke in the United States. Stroke 2003; 34: 2109-12. [PubMed][CrossRef]

15. Jørgensen HS, Nakayama H, Raaschou HO et al. The effect of a stroke unit: reductions in mortality, discharge rate to nursing home, length of hospital stay, and cost. A community-based study. Stroke 1995; 26: 1178 - 82. [PubMed][CrossRef]

16. Fjaertoft H, Indredavik B. Kostnadsvurderinger ved hjerneslag. Tidsskr Nor Lægeforen 2007; 127: 744 - 7. [PubMed] 
Publisert: 17. august 2018. Tidsskr Nor Legeforen. DOI: 10.4045/tidsskr.18.0101 (C) Tidsskrift for Den norske legeforening 2020. Lastet ned fra tidsskriftet.no 